\title{
Temporal Trends in Medical Therapies for ST- and Non-ST Elevation Myocardial Infarction: (From The Atherosclerosis Risk in Communities [ARIC] Surveillance Study)
}

\author{
Emily C. O'Brien, PhD, MSPH ${ }^{1}$, Kathryn M. Rose, $\mathrm{PhD}^{1}$, Chirayath M. Suchindran, $\mathrm{PhD}^{2}$, Til \\ Sturmer, MD, MPH ${ }^{1}$, Patricia P. Chang, MD, MHS ${ }^{3}$, Alvaro Alonso, MD, MPH, $\mathrm{PhD}^{4}$, \\ Christopher D. Baggett, PhD'1, and Wayne D. Rosamond, PhD, MS ${ }^{1}$ \\ ${ }^{1}$ Department of Epidemiology, School of Medicine, University of North Carolina, Chapel Hill, USA \\ ${ }^{2}$ Department of Biostatistics, Gillings School of Global Public Health, University of North Carolina, \\ Chapel Hill, USA \\ ${ }^{3}$ Department of Cardiology, School of Medicine, University of North Carolina, Chapel Hill, USA \\ ${ }^{4}$ Division of Epidemiology and Community Health, School of Public Health, University of \\ Minnesota, Minneapolis, USA
}

\section{Abstract}

Reports from large studies using administrative datasets and event registries have characterized recent temporal trends and treatment patterns for AMI. However, few are population-based and fewer have examined differences in patterns of treatment for patients presenting with ST elevation myocardial infarction (STEMI) and non-ST elevation myocardial infarction (NSTEMI). We examined 22-year trends in the use of 10 medical therapies and procedures by STEMI and NSTEMI classification in 30986 definite or probable MIs in the ARIC Community Surveillance Study from 1987 to 2008. We used weighted multivariable Poisson regression controlling for sex, race/center classification, age, and PREDICT score to estimate average annual percent changes in medical therapy use. From 1987 - 2008, 6106 (19.7\%) hospitalized events were classified as STEMI, and 20302 (65.5\%) were classified as NSTEMI. Among STEMI patients, increases (\%; $95 \% \mathrm{CI})$ were noted in the use of ACE inhibitors $(6.4 ; 5.7,7.2)$, non-aspirin anti-platelets $(5.0$; $4.0,6.0)$, lipid-lowering medications $(4.5 ; 3.1,5.8)$, beta blockers $(2.7 ; 2.4,3.0)$, aspirin $(1.2 ; 1.0$, $1.3)$, and heparin $(0.8 ; 0.4,1.3)$. Among NSTEMI patients, the use of ACE inhibitors (5.5; 5.0, 6.1), non-aspirin anti-platelets $(3.7 ; 2.7,4.7)$, lipid-lowering medications $(3.0 ; 1.9,4.1)$, beta blockers $(4.2 ; 3.9,4.4)$, aspirin $(1.9,1.6 ; 2.1)$, and heparin $(1.7 ; 1.3,2.1)$ increased. Among STEMI patients, we observed decreases in the use of thrombolytics $(-7.2 ;-7.9,-6.6)$ and CABG $(-2.4 \% ;-3.6,-1.2)$. We noted similar increases in PCI and decreases in the use of thrombolytics

(C) 2012 Excerpta Medica, Inc. All rights reserved.

Corresponding Author Contact Information: Emily O'Brien, PhD Duke Clinical Research Institute 2400 Pratt Street Durham, NC 27705 Phone: 919-668-0670 emily.obrien@ duke.edu.

Publisher's Disclaimer: This is a PDF file of an unedited manuscript that has been accepted for publication. As a service to our customers we are providing this early version of the manuscript. The manuscript will undergo copyediting, typesetting, and review of the resulting proof before it is published in its final citable form. Please note that during the production process errors may be discovered which could affect the content, and all legal disclaimers that apply to the journal pertain. 
and CABG among all patients. In conclusion, we found trends of increasing use of evidence-based therapies for both STEMI and NSTEMI patients over the past 22 years.

\section{Keywords}

Epidemiology; myocardial infarction; treatment patterns; reperfusion; temporal trends

\section{Introduction}

The availability of medical therapies for in-hospital management of AMI is increasing annually ${ }^{1,2}$, and the use of these therapies has substantially contributed to the decreasing AMI death rates over the past three decades. ${ }^{3-7}$ Reports from large observational studies have characterized recent temporal trends and treatment patterns for AMI. ${ }^{8-11}$ Conclusions from existing reports have been limited, however, by selection, short follow-up periods, racially and/or geographically homogenous populations, and unvalidated clinical data. Furthermore, few studies have examined differences in temporal trends in the treatment of patients presenting with ST elevation myocardial infarction (STEMI) versus non-ST elevation myocardial infarction (NSTEMI), especially since this redefinition of acute MI resulted in a divergence in treatment recommendations by MI subclass beginning in $2000 .{ }^{12}$ This report characterizes temporal trends in the in-hospital treatment of STEMI and NSTEMI patients over a 22-year period in the Atherosclerosis Risk in Communities (ARIC) Study.

\section{Methods}

The design of the community surveillance component of the Atherosclerosis Risk in Communities (ARIC) study has been described. ${ }^{13,14}$ Briefly, it is a continuous retrospective surveillance study of hospitalized coronary heart disease (CHD) events with mortality follow-up designed to estimate trends in CHD incidence and mortality using standardized criteria and methods in four U.S communities: Forsyth County, NC; Jackson, MS; eight suburbs of Minneapolis, MN; and Washington County, MD. Eligible events included inpatient and out-of-hospital deaths due to CHD and hospitalized nonfatal MI in 35-74 year old residents of these communities. Trained abstractors investigate hospitalizations randomly sampled from annual discharge lists obtained from each hospital serving the four ARIC communities. Events were sampled on age, gender, community of residence and International Classification of Diseases (ICD-9) discharge codes, including 402, 410-414, 427, 428, and 518.4. Collected data items included presenting symptoms; timing of symptom onset; history of MI, angina, and other cardiovascular conditions; in-hospital medications, diagnostics, and medical procedures; laboratory values for a number of relevant cardiac biomarkers; and up to 3 sets of twelve-lead ECG readings. Regular and ongoing inter-abstractor agreement is assessed by evaluating concordance between data elements from a sample of cases abstracted independently by two abstractors. Internal quality control procedures at the ECG reading Center were utilized to ensure reproducibility.

A computerized algorithm using electrocardiogram readings, history of chest pain, and cardiac biomarker levels (total creatinine phosphokinase (CK), creatinine phosophokinase- 
myocardial band (CK-MB), lactate dehydrogenase (LDH), troponin I, and troponin T) was used to assign an MI diagnosis to sampled hospitalized events. This analysis was restricted to events with a Definite or Probable MI diagnosis. Any event with abnormal or equivocal biomarker levels was further classified as ST- or non-ST elevation MI using pain presentation and Minnesota-coded electrocardiogram data from the first, third, or last ECG performed during hospitalization. Multiple hospitalizations occurring within 28 days were combined and treated as one event. Any event requiring review (for example, events where the computer-derived classification of definite MI disagreed with the ICD-9-CM codes for discharge diagnosis) was independently classified by two trained reviewers. Any disagreements in diagnoses were then adjudicated by a third reviewer.

Medications and procedures were obtained from hospital pharmacy records and medical record review during the abstraction process. Our analysis included data on 7 medication classes: aspirin, beta blockers, calcium channel blockers, angiotensin-converting enzyme (ACE) inhibitors, lipid-lowering medications, non-aspirin anti-platelet agents, and heparin; and 4 revascularization procedures: coronary artery bypass grafting (CABG), thrombolytic therapy (intracoronary or intravenous streptokinase, urokinase, anistreplase, anisoylated plasminogen streptokinase activator complex [APSAC], or tissue plasminogen activator [TPA]), and coronary angioplasty (PCI) with or without the implantation of a stent. Each medication or procedure was classified as any receipt during hospitalization or at discharge (yes or no). Because abstraction of several therapies of interest began after 1987, trends for the following therapies were estimated beginning with the first study year for which complete treatment information was available for all sampled events: heparin (beginning in 1992), ACE inhibitors (1992), non-aspirin anti-platelets (1997), lipid-lowering medications (1999) and stent implantation (1999).

Patient demographics were obtained from medical record reviews. Demographics of interest included gender (male or female), race (black or white/other) and age. Clinical comorbidities including prior MI, hypertension, diabetes mellitus, and stroke were collected. In order to adjust for disease severity and clinical comorbidity, we utilized a modified Predicting Risk of Death in Cardiac Disease Tool (PREDICT) score. ${ }^{15}$ The score is a validated metric that predicts mortality in acute coronary syndrome patients from clinical presentation data, including cardiogenic shock, history of MI or cardiac procedures, age, severity of electrocardiographic changes, congestive heart failure, and Charlson Comorbidity Index. Data on renal function were not collected and therefore were omitted from our PREDICT score calculation.

We excluded patients whose race was not classified as black or white $(n=658)$ and due to insufficient sample sizes, black patients who were sampled in Minnesota or Washington County, Maryland $(n=493)$. After these exclusions, the final sample size for analysis was 30,986 definite or probable MI events.

All estimates presented are weighted to account for the ARIC surveillance sampling scheme. ${ }^{13}$ We examined changes in study population characteristics over the study period using chi-square tests for independence with robust variance estimation to account for the complex sampling scheme. The proportion of patients receiving each medication and 
procedure were calculated for all study years using weighted Poisson regression, with estimates age-standardized to the 2000 US Census age distribution. We used multivariable loglinear regression to estimate average annual percent increases or decreases for each medical therapy overall and among STEMI and NSTEMI patients. In the figures, we present medication and procedure use for each study year; however, for ease of reporting and to promote stability in confidence interval estimates, events were grouped into intervals of 5, 6, or 7 years for table presentation. To account for the complex sampling scheme, all analyses were conducted using SAS-callable SUDAAN (release 9.2; Research Triangle Institute, Research Triangle Park, North Carolina).

\section{Results}

Table 1 shows selected study population characteristics over time in 5-year intervals. From 1987 to 2008, 30,986 definite or probable MI events were sampled in the four study communities. Of these, 6106 (19.7\%) were classified as STEMI, and 20302 (65.5\%) were classified as NSTEMI. The proportion of patients classified as neither STEMI nor NSTEMI $(14.8 \%)$ remained stable over the study period, as did gender and age distribution. Mean length of stay in days $(95 \% \mathrm{CI})$ decreased substantially over the study period, as did the prevalence hypertension, diabetes, and stroke all increased throughout the study period.

Table 2 presents the proportion of patients receiving each medication and procedure of interest by year, age-standardized to the 2000 US Census population. We observed increases in the use of all medications and procedures except for calcium channel blockers and thrombolytic therapy, both of which decreased throughout the study period. Data on the use of stents was first collected in 1998. Since then, the proportion of all MI patients receiving stents doubled. Temporal trends for all patients and for STEMI/NSTEMI patients are illustrated for selected medications and procedures in Figure 1.

Figure 2 presents the average annual percentage change in the use of 7 medications and 4 procedures in ARIC surveillance from 1987-2008 by STEMI and NSTEMI classification, adjusted for sex, age, race*center classification, and PREDICT score. (Note: a reported percent change of 5\% indicates an increase of 5\% per year on average in the use of that particular medication or procedure during the study period). Similar trends were seen among STEMI and NSTEMI patients: increases (\%) were noted in the use of ACE inhibitors, nonaspirin anti-platelet agents, lipid-lowering medications, beta blockers, aspirin, and heparin, Calcium channel blocker use decreased for both STEMI and NSTEMI patients over the study period. Temporal trends in the receipt of reperfusion and revascularization procedures were also similar for STEMI and NSTEMI patients. There were decreases in the use of thrombolytics and CABG. PCI and stent use increased for both STEMI and NSTEMI patients.

Finally, we examined reperfusion and revascularization rates in in male and female STEMI and NSTEMI patients. Risk ratios and 95\% CIs comparing receipt of any reperfusion/ revascularization strategy (PCI, PCI with stent, $\mathrm{CABG}$, or thrombolytics) among men versus women for each study year are shown in Figure 3. Crude rates of reperfusion/ revascularization were higher among men than among women for all study years. However, 
after adjustment for age, race*center, PREDICT score, and STEMI/NSTEMI classification, we did not observe significant differences in rates of revascularization across gender strata.

\section{Discussion}

This is the first study to present long-term trends in-hospital treatment for both STEMI and NSTEMI patients using validated clinical data. The ARIC community surveillance study offers several advantages in the estimation of in-hospital MI treatment trends, including its large, geographically and racially diverse population, 22 years of follow-up, populationbased sampling scheme, and detailed clinical event data and validated MI diagnostics.

We observed an increase in the use of 6 of 7 medications over the study period among STEMI and NSTEMI patients. The largest increases were in ACE inhibitors, non-aspirin anti-platelets, lipid-lowering medications, and beta-blockers. Smaller increases were noted for aspirin and heparin. These increases were significant after adjustment for age, gender, race and study center, and PREDICT score, did not differ by MI subclass, and are consistent with findings from other populations documenting increases in the use of aspirin ${ }^{10,11,16}$, beta-blockers ${ }^{8,10,11}$, and ACE inhibitors ${ }^{8,10,11,17}$ _ENREF_6. Calcium channel blockers were the only class of medications for which we observed a decrease. The magnitude of decrease was similar to that reported in other populations. ${ }^{8,11}$ The overall results of increasing use of evidence-based pharmacological interventions for hospitalized MI are consistent with those of other studies reporting trends in increasing quality of care and better guideline adherence for acute MI patients. ${ }^{18,19}$

A number of studies of revascularization in AMI conducted in the early 1990's reported persistent gender disparities in the receipt of PCI, CABG, and/or thrombolytics. ${ }^{20-22} \mathrm{We}$ compared receipt of any revascularization strategy among men and women over the study period. Crude estimates indicated that men were more likely than women to receive revascularization at all time points. However, after adjustment for age, race*center, PREDICT score and STEMI classification, we no longer observed significant differences in the use of any revascularization strategy in women compared to men. These findings are consistent with those of several studies that suggest gender differences in revascularization rates may be accounted for by other clinical variables and event characteristics. ${ }^{23-25}$

This study also presents trends in pharmaceutical treatments and reperfusion procedures by MI subclass. NSTEMI and STEMI were introduced as subclasses for acute MI in $2000{ }^{26}$ While both STEMI and NSTEMI release markers of necrosis that reflect acute MI, a classification of STEMI indicates transmural myocardial ischemia or necrosis as evidenced by ST-elevation electrocardiographic data. Few studies have examined long-term trends in management of NSTEMI and STEMI. Data from the National Registry of Myocardial Infarction (1990-2006) reported similar improvements in quality of care over the study period for STEMI and NSTEMI patients. ${ }^{18}$

PCI use increased markedly among STEMI patients after 1999, contemporaneous to the publication of the AHA 1999 Update to Guidelines for the Management of Patients with Acute Myocardial Infarction, which recommended balloon inflation for PCI within 90 
minutes of hospital arrival for eligible patients. The use of thrombolytics increased after the 1987-1990 time period for both STEMI and NSTEMI patients, concurrent with the publication of results from two European trials, GISSI (1986) and ISIS-2 (1988), which reported mortality reductions with thrombolytics compared to placebo. ${ }^{27,28}$ However, the use of thrombolytics declined sharply after 1994, following the publication of a number of trials reporting better clinical outcomes among patients treated with angioplasty compared to those treated with thrombolytics. ${ }^{29}$ _ENREF_30

This study has a number of limitations. First, because the structure of the medication data element captures medications prescribed at any point during hospitalization or at discharge, we did not have information on timing of administration. This limited our ability to make comparisons between early or delayed medication use. We were also unable to distinguish between medication use during hospitalization and at discharge. An additional limitation of this study is the possibility of confounding by indication. Because we do not have data on eligibility for each medication of interest, we were unable to examine the impact of patientspecific indications on temporal trends in MI therapy. However, we did assess changes in the comorbidity burden in this population by analyzing temporal trends in mean PREDICT score, a validated score that includes a comorbidity index and clinical event data. We did not observe significant changes in mean PREDICT score over time for among STEMI or NSTEMI patients.

\section{References}

1. Boersma E, Mercado N, Poldermans D, Gardien M, Vos J, Simoons ML. Acute myocardial infarction. Lancet. 2003; 361:847-858. [PubMed: 12642064]

2. Roe MT, Messenger JC, Weintraub WS, Cannon CP, Fonarow GC, Dai D, Chen AY, Klein LW, Masoudi FA, McKay C, Hewitt K, Brindis RG, Peterson ED, Rumsfeld JS. Treatments, trends, and outcomes of acute myocardial infarction and percutaneous coronary intervention. J Am Coll Cardiol. 2010; 56:254-263. [PubMed: 20633817]

3. Goldman L, Cook EF. The decline in ischemic heart disease mortality rates. An analysis of the comparative effects of medical interventions and changes in lifestyle. Ann Intern Med. 1984; 101:825-836. [PubMed: 6388454]

4. Hunink MG, Goldman L, Tosteson AN, Mittleman MA, Goldman PA, Williams LW, Tsevat J, Weinstein MC. The recent decline in mortality from coronary heart disease, 1980-1990. The effect of secular trends in risk factors and treatment. JAMA. 1997; 277:535-542. [PubMed: 9032159]

5. Hajjar I, Kotchen TA. Trends in prevalence, awareness, treatment, and control of hypertension in the United States, 1988-2000. JAMA. 2003; 290:199-206. [PubMed: 12851274]

6. Ford ES, Ajani UA, Croft JB, Critchley JA, Labarthe DR, Kottke TE, Giles WH, Capewell S. Explaining the decrease in U.S. deaths from coronary disease, 1980-2000. N Engl J Med. 2007; 356:2388-2398. [PubMed: 17554120]

7. Setoguchi S, Glynn RJ, Avorn J, Mittleman MA, Levin R, Winkelmayer WC. Improvements in long-term mortality after myocardial infarction and increased use of cardiovascular drugs after discharge: a 10-year trend analysis. J Am Coll Cardiol. 2008; 51:1247-1254. [PubMed: 18371553]

8. Rogers WJ, Canto JG, Lambrew CT, Tiefenbrunn AJ, Kinkaid B, Shoultz DA, Frederick PD, Every $\mathrm{N}$. Temporal trends in the treatment of over 1.5 million patients with myocardial infarction in the US from 1990 through 1999: the National Registry of Myocardial Infarction 1, 2 and 3. J Am Coll Cardiol. 2000; 36:2056-2063. [PubMed: 11127441]

9. Furman MI, Dauerman HL, Goldberg RJ, Yarzebski J, Lessard D, Gore JM. Twenty-two year (1975 to 1997) trends in the incidence, in-hospital and long-term case fatality rates from initial Q-wave 
and non-Q-wave myocardial infarction: a multi-hospital, community-wide perspective. J Am Coll Cardiol. 2001; 37:1571-1580. [PubMed: 11345367]

10. Burwen DR, Galusha DH, Lewis JM, Bedinger MR, Radford MJ, Krumholz HM, Foody JM. National and state trends in quality of care for acute myocardial infarction between 1994-1995 and 1998-1999 - The Medicare Health Care Quality Improvement Program. Arch Intern Med. 2003; 163:1430-1439. [PubMed: 12824092]

11. McGovern PG, Jacobs DR, Shahar E, Arnett DK, Folsom AR, Blackburn H, Luepker RV. Trends in acute coronary heart disease mortality, morbidity, and medical care from 1985 through 1997 The Minnesota Heart Survey. Circulation. 2001; 104:19-24. [PubMed: 11435332]

12. Alpert JS, Antman E, Apple F, Armstrong PW, Bassand JP, de Luna AB, Beller G, Breithardt G, Chaitman BR, Clemmensen P, Falk E, Fishbein MC, Galvani M, Garson A, Grines C, Hamm C, Hoppe U, Jaffe A, Katus H, Kjekshus J, Klein W, Klootwijk P, Lenfant C, Levy D, Levy RI, Luepker R, Marcus F, Naslund U, Ohman M, Pahlm O, Poole-Wilson P, Popp R, Pyorala K, Ravkilde J, Rehnquist N, Roberts W, Roberts R, Roelandt J, Ryden L, Sans S, Simoons ML, Thygesen K, Tunstall-Pedoe H, Underwood R, Uretsky BF, de Werf FV, Voipio-Pulkki LM, Wagner G, Wallentin L, Wijns W, Wood D, Amer JESC. Myocardial infarction redefined - A consensus document of the Joint European Society of Cardiology/American College of Cardiology Committee for the Redefinition of Myocardial Infarction. Eur Heart J. 2000; 21:1502-1513. [PubMed: 10973764]

13. White AD, Folsom AR, Chambless LE, Sharret AR, Yang K, Conwill D, Higgins M, Williams OD, Tyroler HA. Community surveillance of coronary heart disease in the atherosclerosis risk in communities (ARIC) study: Methods and initial two years' experience. J Clin Epidemiol. 1996; 49:223-233. [PubMed: 8606324]

14. Rosamond WD, Chambless LE, Sorlie PD, Bell EM, Weitzman S, Smith JC, Folsom AR. Trends in the sensitivity, positive predictive value, false-positive rate, and comparability ratio of hospital discharge diagnosis codes for acute myocardial infarction in four US communities, 1987-2000. Am J Epidemiol. 2004; 160:1137-1146. [PubMed: 15583364]

15. Jacobs DR Jr. Kroenke C, Crow R, Deshpande M, Gu DF, Gatewood L, Blackburn H. PREDICT: A simple risk score for clinical severity and long-term prognosis after hospitalization for acute myocardial infarction or unstable angina: the Minnesota heart survey. Circulation. 1999; 100:599607. [PubMed: 10441096]

16. Jackson EA, Sivasubramian R, Spencer FA, Yarzebski J, Lessard D, Gore JM, Goldberg RJ. Changes over time in the use of aspirin in patients hospitalized with acute myocardial infarction (1975 to 1997): A population-based perspective. Am Heart J. 2002; 144:259-268. [PubMed: 12177643]

17. Perschbacher JM, Reeder GS, Jacobsen SJ, Weston SA, Killian JM, Slobodova A, Roger VL. Evidence-based therapies for myocardial infarction: Secular trends and determinants of practice in the community. Mayo Clin Proc. 2004; 79:983-991. [PubMed: 15301324]

18. Peterson ED, Shah BR, Parsons L, Pollack CV, French WJ, Canto JG, Gibson CM, Rogers WJ, Investigators $\mathrm{N}$. Trends in quality of care for patients with acute myocardial infarction in the National Registry of Myocardial Infarction from 1990 to 2006. Am Heart J. 2008; 156:1045-1055. [PubMed: 19032998]

19. Roe MT, Messenger JC, Weintraub WS, Cannon CP, Fonarow GC, Dai D, Chen AY, Klein LW, Masoudi FA, McKay C, Hewitt K, Brindis RG, Peterson ED, Rumsfeld JS. Treatments, Trends, and Outcomes of Acute Myocardial Infarction and Percutaneous Coronary Intervention. J Am Coll Cardiol. 2010; 56:254-263. [PubMed: 20633817]

20. Ayanian JZ, Epstein AM. Differences in the Use of Procedures between Women and Men Hospitalized for Coronary Heart-Disease. New Engl J Med. 1991; 325:221-225. [PubMed: 2057022]

21. Vaccarino V, Rathore SS, Wenger NK, Frederick PD, Abramson JL, Barron HV, Manhapra A, Mallik S, Krumholz HM, Infarctio NRM. Sex and racial differences in the management of acute myocardial infarction, 1994 through 2002. New Engl J Med. 2005; 353:671-682. [PubMed: 16107620] 
22. Wong CC, Froelicher ES, Bacchetti P, Barron HV, Gee L, Selby JV, Lundstrom R, Swain B, Truman A. Influence of gender on cardiovascular mortality in acute myocardial infarction patients with high indication for coronary angiography. Circulation. 1997; 96:51-57.

23. Rathore SS, Wang YF, Radford MJ, Ordin DL, Krumholz HM. Sex differences in cardiac catheterization after acute myocardial infarction: The role of procedure appropriateness. Ann Intern Med. 2002; 137:487-493. [PubMed: 12230349]

24. Lincoff AM, Califf RM, Ellis SG, Sigmon KN, Lee KL, Leimberger JD, Topol EJ. Thrombolytic Therapy for Women with Myocardial-Infarction - Is There a Gender-Gap. J Am Coll Cardiol. 1993; 22:1780-1787. [PubMed: 8245328]

25. Ghali WA, Faris PD, Galbraith D, Norris CM, Curtis MJ, Saunders LD, Dzavik V, Mitchell LB, Knudtson ML, Outcome APP. Sex differences in access to coronary revascularization after cardiac catheterization: Importance of detailed clinical data. Ann Intern Med. 2002; 136:723-732. [PubMed: 12020140]

26. Alpert JS, Antman E, Apple F, Armstrong PW, Bassand JP, de Luna AB, Beller G, Breithardt G, Chaitman BR, Clemmensen P, Falk E, Fishbein MC, Galvani M, Garson A, Grines C, Hamm C, Jaffe A, Katus H, Kjekshus J, Klein W, Klootwijk P, Lenfant C, Levy D, Levy RI, Luepker R, Marcus F, Naslund U, Ohman M, Pahlm O, Poole-Wilson P, Popp R, Alto P, Pyorala K, Ravkilde J, Rehnquist N, Roberts W, Roberts R, Roelandt J, Ryden L, Sans S, Simoons ML, Thygesen K, Tunstall-Pedoe H, Underwood R, Uretsky BF, Van de Werf F, Voipio-Pulkki LM, Wagner G, Wallentin L, Wijns W, Wood D, Ame JESC. Myocardial infarction redefined - A consensus Document of the Joint European Society of Cardiology/American College of Cardiology Committee for the Redefinition of Myocardial Infarction. J Am Coll Cardiol. 2000; 36:959-969. [PubMed: 10987628]

27. Effectiveness of Intravenous Thrombolytic Treatment in Acute Myocardial-Infarction. Lancet. 1986; 1:397-402. [PubMed: 2868337]

28. Randomized Trial of Intravenous Streptokinase, Oral Aspirin, Both, or Neither among 17,187 Cases of Suspected Acute Myocardial-Infarction - Isis-2. J Am Coll Cardiol. 1988; 12:A3-A13.

29. Weaver WD, Simes RJ, Betriu A, Grines CL, Zijlstra F, Garcia E, Grinfeld L, Gibbons RJ, Ribeiro EE, DeWood MA, Ribichini F. Comparison of primary coronary angioplasty and intravenous thrombolytic therapy for acute myocardial infarction - A quantitative review. JAMA. 1997; 278:2093-2098. [PubMed: 9403425] 

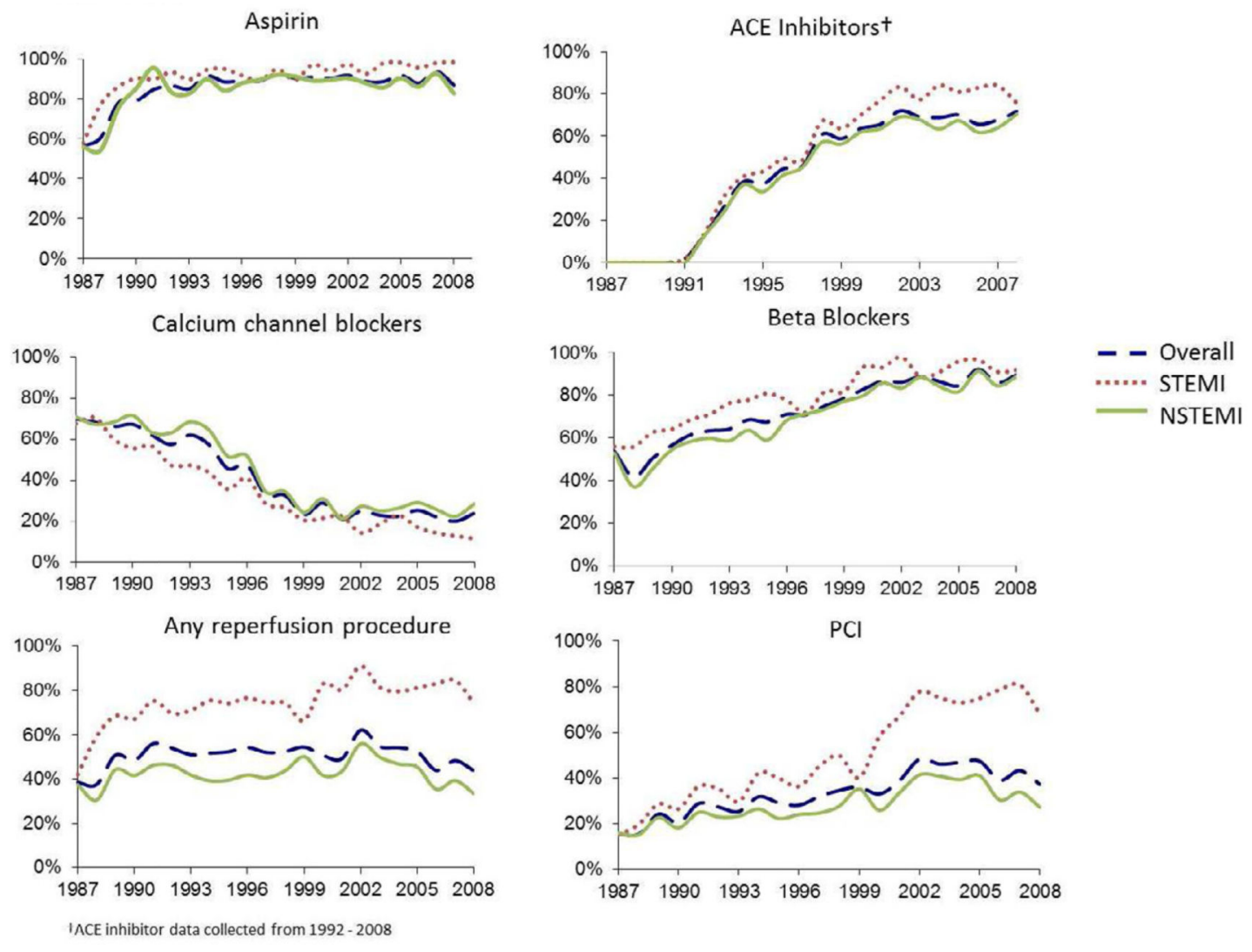

Figure 1.

Medication and procedure use by year in STEMI and NSTEMI patients in the ARIC surveillance study: $1987-2008$. 


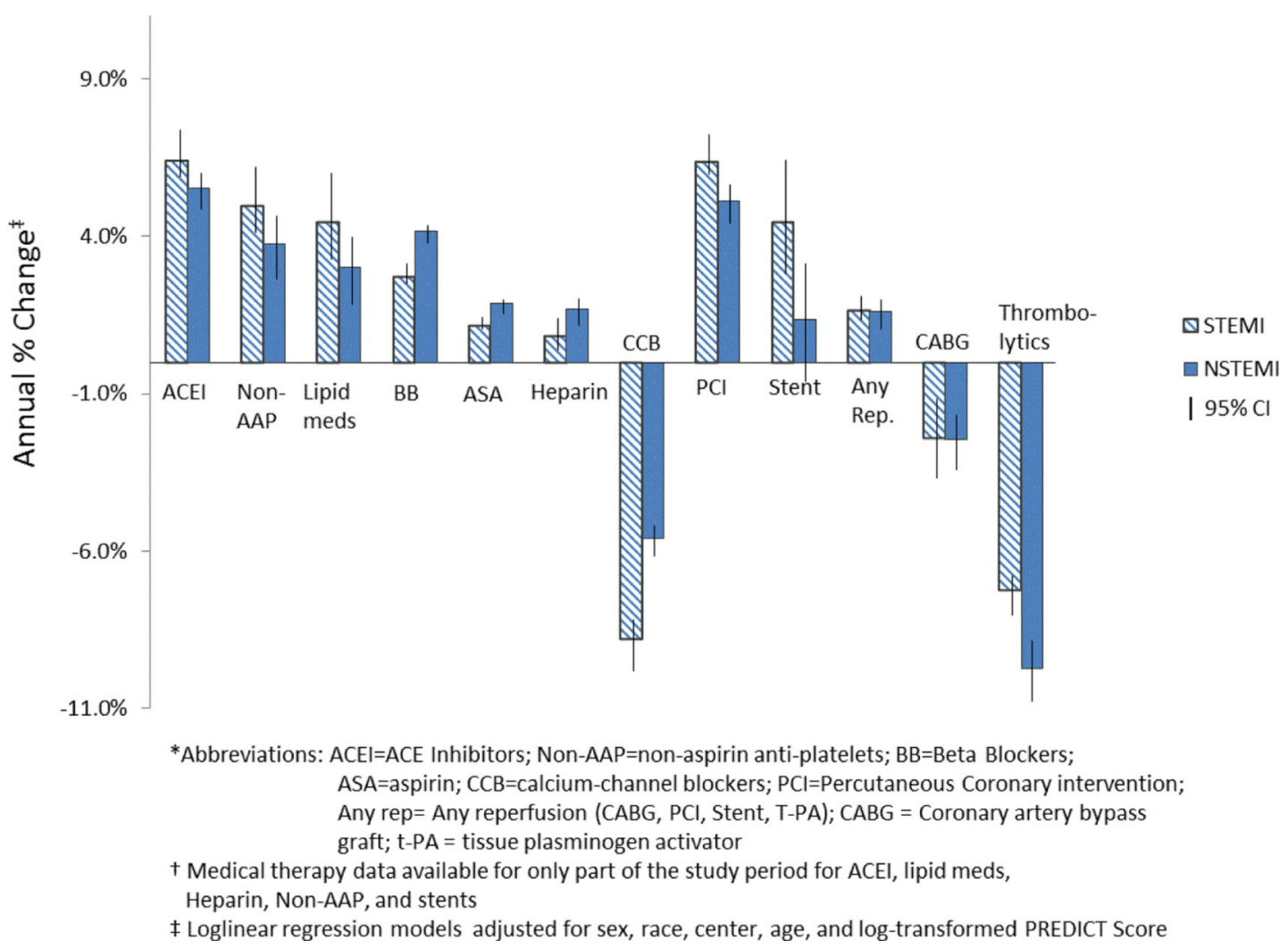

Figure 2.

Average annual \% change in medical therapy and reperfusion procedure use in STEMI and NSTEMI patients in the ARIC surveillance study: 1987 - 2008. 

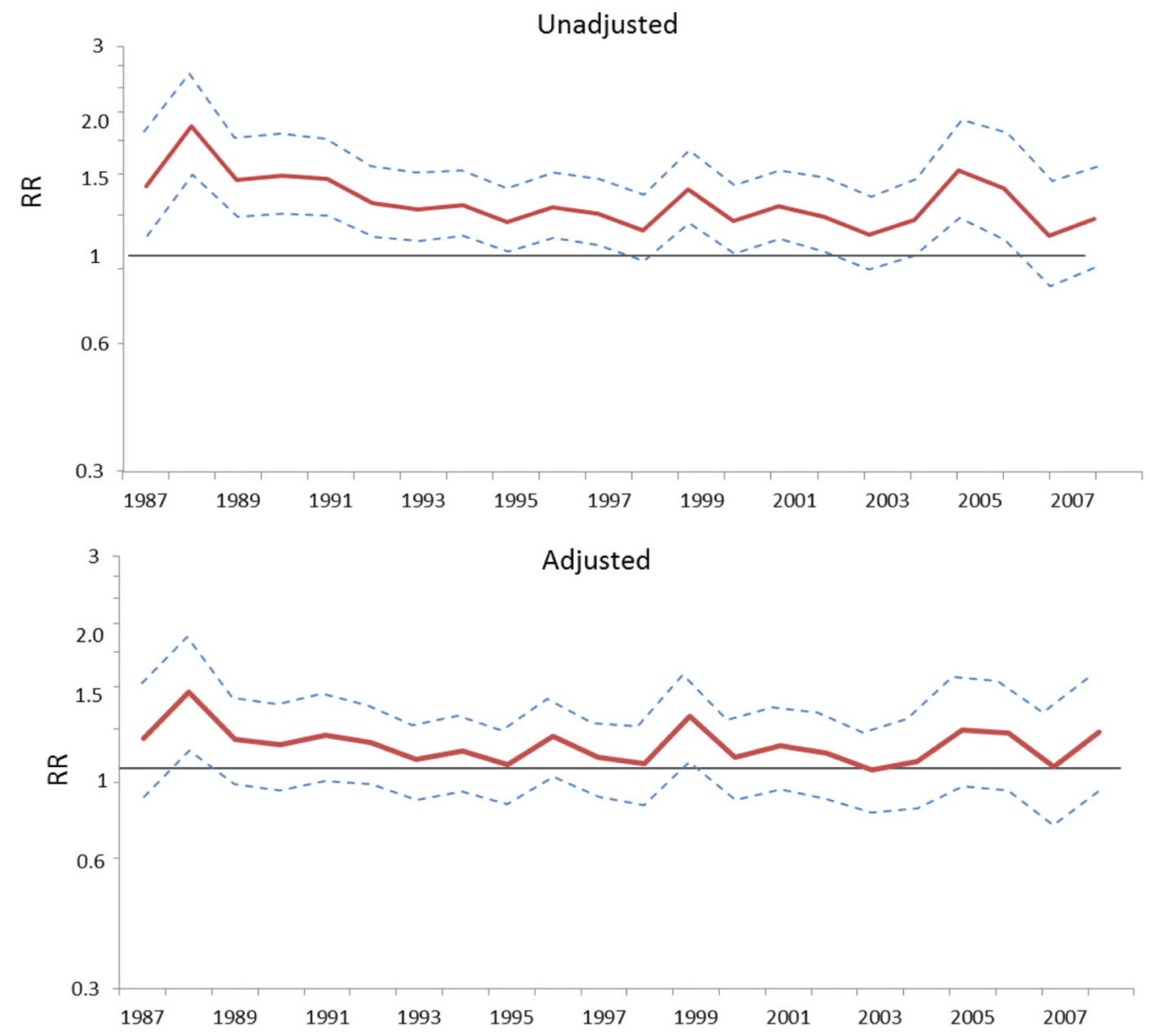

*Eligible reperfusion strategies included thrombolytics, $\mathrm{PCl}$ with or without stents, and CABG † Weighted loglinear regression adjusting for age, race, center, PREDICT score, and STEMI classification

Figure 3.

Adjusted and unadjusted temporal trends in risk ratios comparing receipt of any reperfusion strategy in men versus women in the ARIC surveillance study: 1987 - 2008. 

斑|

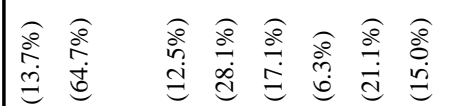

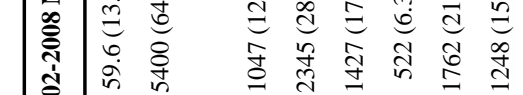

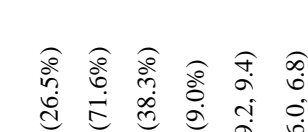

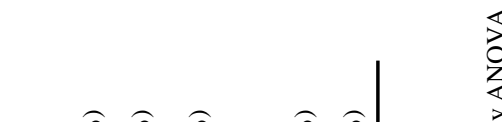

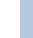




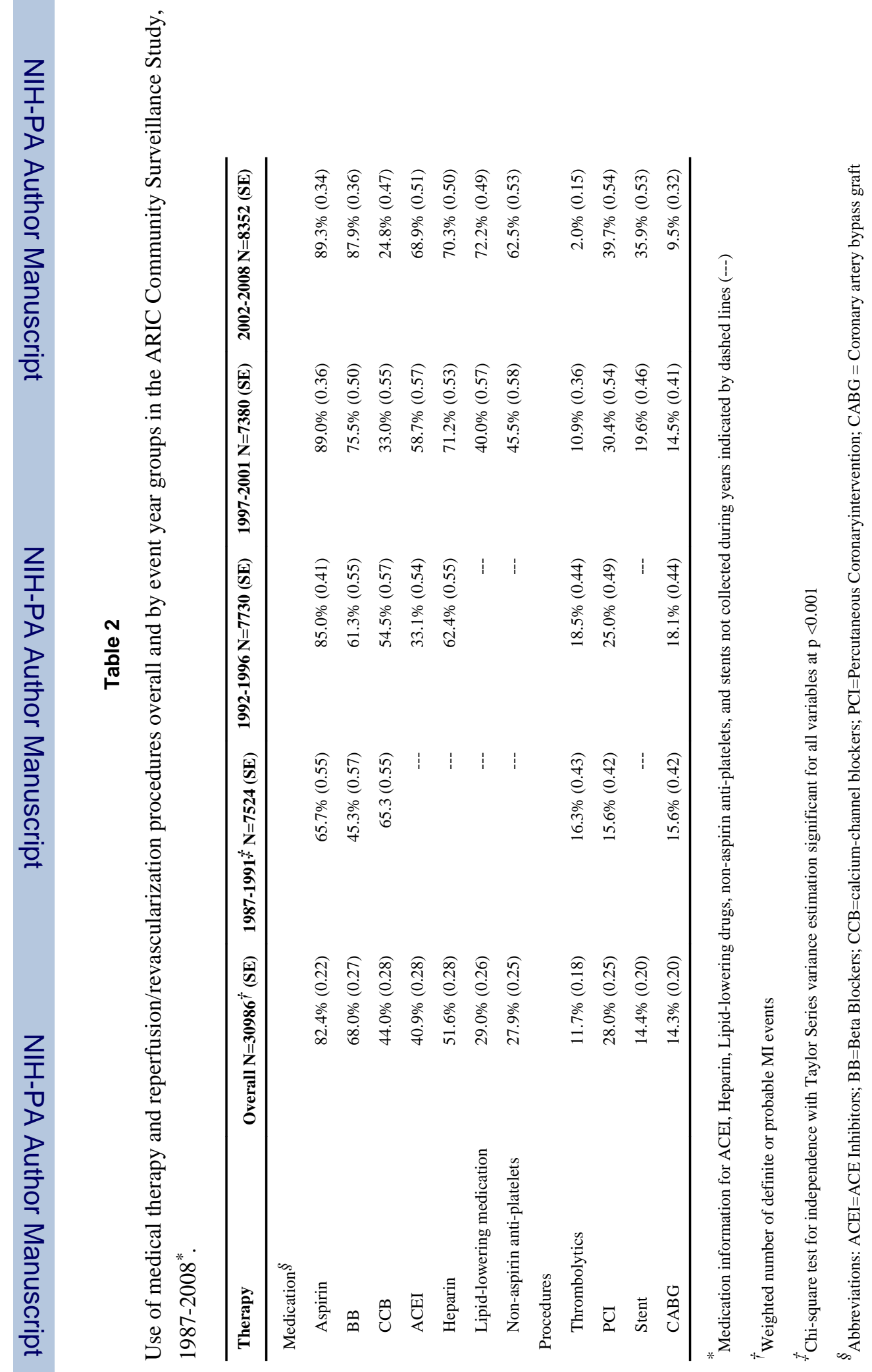

